\title{
Epidural anaesthesia does not mask early signs of uterine rupture
}

McCarter J*, Merjavy P, Winter C

Craigavon Area Hospital, Portadown

*jmccarter01@qub.ac.uk

\section{Introduction}

Uterine rupture is a rare, life threatening complication of labour that has an incidence of $0.5 \%$ for parturients attempting trial of labour after caesarian section (TOLAC) ${ }^{1}$. It requires high index of suspicion in order to diagnose early.

Rupture results in foetal bradycardia and CTG abnormalities, maternal haemorrhage and hypotension, uterine atony, and a change in contractions or pain that does not diminish between contractions. ${ }^{2}$ This change in pain is usually a late sign - potentially due to inability to distinguish it from labour pains.

In our case the pain of rupture was not masked by epidural analgesia, but this was incorrectly assumed to be epidural failure. We suggest that impending scar rupture should always be considered when breakthrough pain occurs despite epidural analgesia.

Epidural analgesia can assist rather than obscure the diagnosis of uterine rupture, could potentially lead to an earlier diagnosis, earlier caesarian section (CS) and result in a reduction in maternal and foetal morbidity and mortality.

\section{Case Report}

We present the case of a 31 year old para 1+0 who attended at term for a TOLAC. The patient had a surgical history of emergency CS 3 years previously.

Patient requested epidural while at $3 \mathrm{~cm}$ cervical dilation. This was sited at $\mathrm{L} 2 / 3$ interspace without immediate complication. A bilateral block to cold at T8 was reached after a test dose of $3 \mathrm{ml} 0.25 \%$ Levobupivacaine and a loading dose of a further $7 \mathrm{ml}$ plus $50 \mathrm{mcg}$ Fentanyl. An infusion of $0.1 \%$ Levobupivacaine $+2 \mathrm{mcg} / \mathrm{ml}$ fentanyl was started at $10 \mathrm{ml} / \mathrm{hr}$ as per local guidelines. The patient was noted to be comfortable and relaxed after onset of blockade.

3 hours later the patient was reporting severe abdominal pain despite continued infusion. On assessment she had a block height of T9/T10, was visibly distressed and requiring Entonox constantly. A bolus of $9 \mathrm{ml} 0.25 \%$ Levobupivicaine $+50 \mathrm{mcg}$ Fentanyl was given over $5 \mathrm{~min}$ to improve the epidural block. Blood pressure remained stable.

25 minutes later a Category-1 CS was called for due to sustained foetal bradycardia. Intra-uterine foetal resuscitation measures were commenced en route to theatre (fluid bolus, left lateral decubitus position and oxygen). On arrival foetal heart rate had improved, and the decision was made to attempt regional anaesthesia. Severe abdominal pain was still described despite recent epidural top-up, therefore epidural was removed and a spinal anaesthetic was sited. $2.3 \mathrm{ml}$ Heavy Marcaine $+250 \mathrm{mcg}$ Diamorphine were inserted intrathecally.

8 minutes after spinal, the patient was still reporting severe abdominal pain. Further signs of foetal distress were noted and due to the increased urgency of delivery a failed spinal was declared and general anaesthesia was induced.

On opening the abdomen it was noted that uterine rupture had occurred. The foetus was delivered without incident (Apgar scores 6/9 at 1/5 minutes respectively) and surgery was completed with an estimated blood loss of $1200 \mathrm{ml}$. The patient emerged from anaesthesia without incident and was comfortable post operatively in recovery.
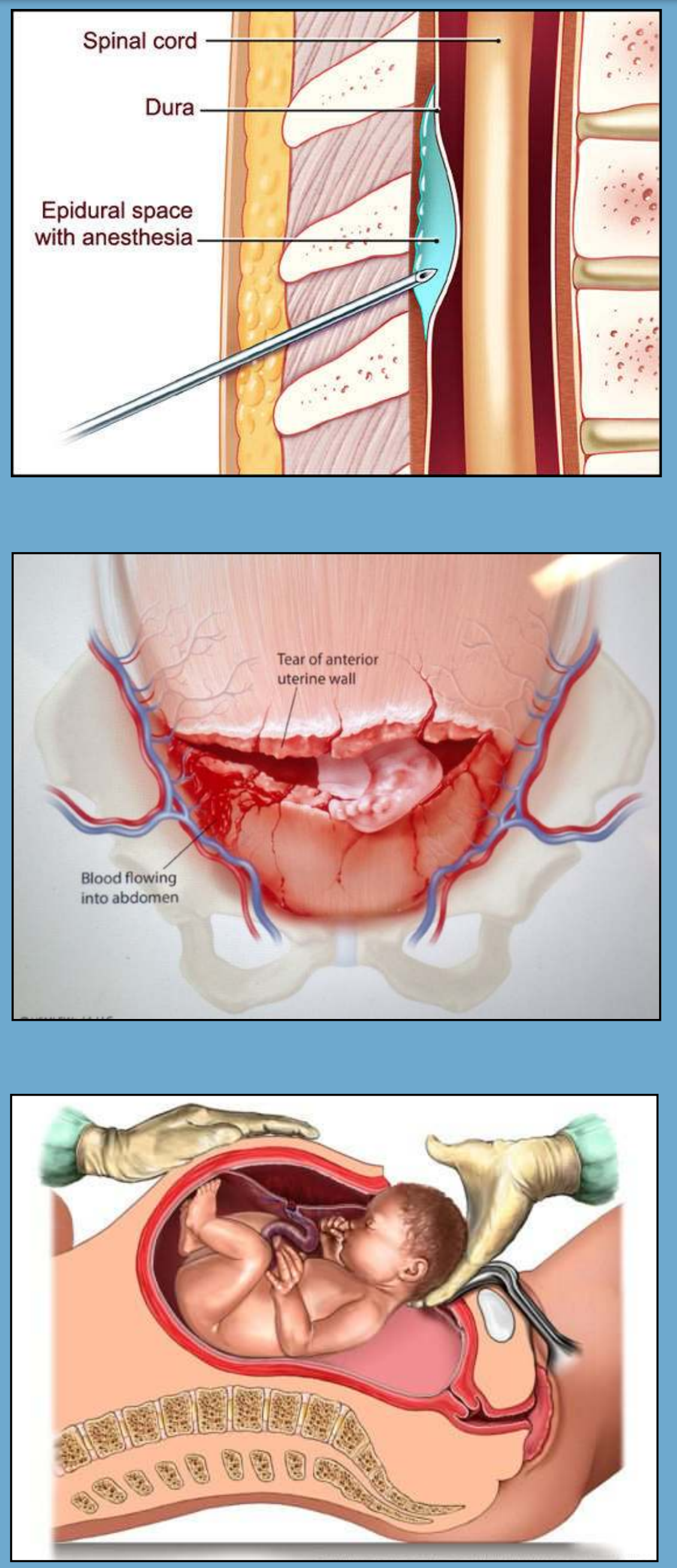

\section{Discussion}

In this case the first sign of uterine rupture was severe abdominal pain despite a working epidural. Foetal distress occurred secondary to this.

We therefore highlight that there should be a high index of suspicion of uterine rupture when breakthrough pain occurs despite a functioning epidural.

\section{References}

1. Al-Zirqi I, Stray-Pedersen B, Forsén L, Vangen S. Uterine rupture after previous caesarean section. BJOG 2010;117:809-820.

2. Zakowski M, Dailey $P$, Jackson S. Managing the risk of uterine rupture during a trial of labor after cesarean section. CSA Bull. 2011;61 (1):66-76 